collection, the patient was started on intravenous cefotaxime and transferred back to Torbay for further care. He received a total of three weeks of intravenous antibiotics and, at follow up five weeks following surgery, his computed tomogram had returned to normal and he was symptom free. During his recovery, he recalled an incident two years previously when he had been struck on the head while playing football and had lost consciousness. He did not obtain medical help after this and had no postconcussion symptoms.

Extradural haematomas are normally the result of trauma to the head and typically present with signs and symptoms of rapidly increasing intracranial pressure. The term chronic extradural haematomas is usually reserved for those haematomas that exist for more than 13 days after trauma ${ }^{1}$ but there is no precise definition. They represent $7 \%$ to $14 \%^{23}$ of extradural haematomas and, in almost a quarter of patients, the cause is not determined. ${ }^{3}$ Infection of the extradural space is extremely uncommon but there is a recognised association of extradural abscess formation with chronic sinusitis and with otitis media. Secondary infection of a chronic extra- dural haematoma is, however, unreported. $S$ anginosus, one of the Streptococcus milleri group of organisms, is considered to be commensal and is associated with abscesses and purulent infections particularly affecting the cardiac, abdominal, skin, and central nervous systems. ${ }^{4}$ The organisms are usually sensitive to common antibiotics but surgical evacuation is usually necessary when there is abscess formation.

Our patient had a chronic extradural haematoma, which we assumed to be a result of his head injury two years previously. The source of his infection is not entirely clear but it is conceivable that he had a transient bacteraemia that resulted in colonisation of his haematoma. We recommend that when assessing patients with a suspected space occupying lesion, an extended history should be taken looking for evidence of a traumatic origin.

1 Iwakuma T, Brunngraber CV. Chronic extradural haematomas. J Neurosurg 1973;38:488-93.

2 Tatagiba M, Sepehrnia A, Azm M, et al. Chronic epidural hematoma-report on eight cases and review of the literature. Surg Neurol 1989;32:453-83.

3 Viljoen JJ, Wessels LS. Subacute and chronic extradural haematomas. S Afr J Surg 1990;28:133-7.

4 Pisitelli SC, Shwed J, Schreckenberger P, et al. Streptococcus milleri group: renewed interest in an elusive pathogen. Eur J Clin Microbiol Infect Dis 1992;11:491-8.
Department of Accident and Emergency Medicine, Norfolk and Norwich Hospital, Norfolk NR1 3SR

Correspondence to: Mr Inyang, Specialist Registrar.

\title{
Unusual cause of a raised right hemidiaphragm
}

\author{
V Inyang
}

A 31 year old woman was brought by ambulance after a road traffic accident. She had been the driver of a car travelling at 50 mph before collision with a tree. The paramedics reported significant intrusion of the driver's door towards the patient's right chest wall.

On examination she had a tachypnoea of $24 / \mathrm{min}$, diminished breath sounds in the right lung base, and a pulse rate of $113 / \mathrm{min}$. A chest radiograph revealed a raised right hemidiaphragm (fig 1). The patient stabilised haemodynamically with a 2 litre crystalloid infusion.

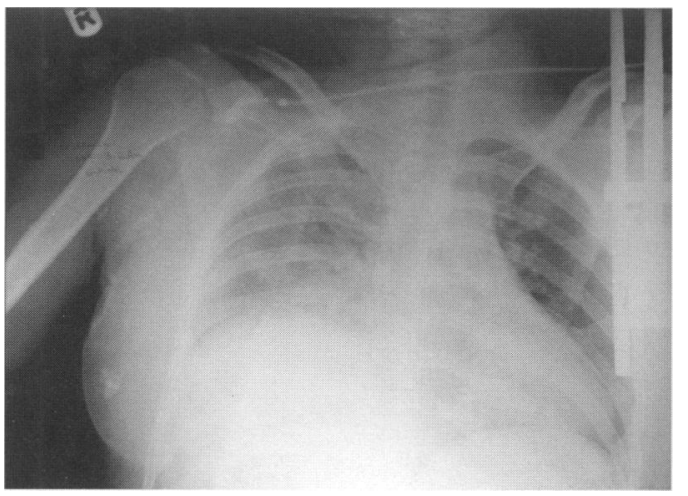

Figure 1 Chest radiograph showing raised right hemidiaphragm.
She was nursed on a high dependency unit overnight.

Thoracoscopy in the morning was negative. Abdominal computed tomography showed a liver haematoma (fig 2). This presentation has not been previously reported. The patient made a good recovery with conservative management.

In stable patients computed tomography remains a valuable tool for the non-invasive definition of pulmonary, diaphragmatic, and abdominal visceral injury.

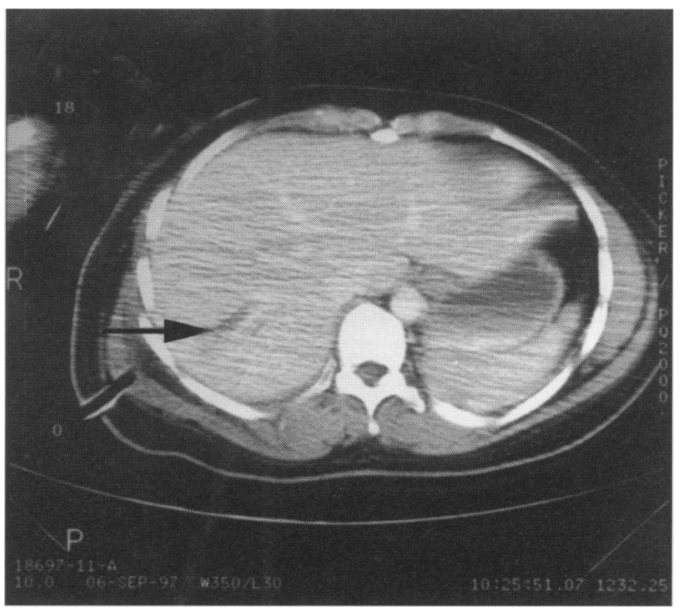

Figure 2 Computed tomography showing the liver laceration (arrow). 